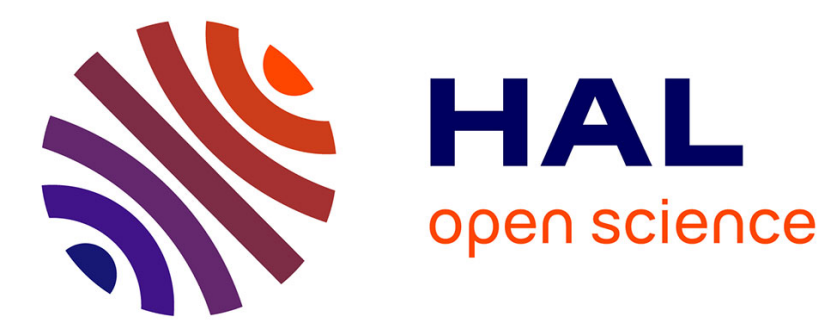

\title{
On modal tenses and tensed modals
}

\author{
Brenda Laca
}

\section{To cite this version:}

Brenda Laca. On modal tenses and tensed modals. Ch. Nishida / C. Russi. Building a bridge between linguistic communities of the Old and the New World. Current research in tense, aspect, mood and modality, Rodopi, pp.163-198, 2012, Cahiers Chronos. halshs-00323340v2

\section{HAL Id: halshs-00323340 \\ https://shs.hal.science/halshs-00323340v2}

Submitted on 4 May 2010

HAL is a multi-disciplinary open access archive for the deposit and dissemination of scientific research documents, whether they are published or not. The documents may come from teaching and research institutions in France or abroad, or from public or private research centers.
L'archive ouverte pluridisciplinaire HAL, est destinée au dépôt et à la diffusion de documents scientifiques de niveau recherche, publiés ou non, émanant des établissements d'enseignement et de recherche français ou étrangers, des laboratoires publics ou privés. 


\title{
On modal tenses and tensed modals*
}

\author{
Brenda LACA
}

Université Paris 8 - CNRS UMR 7023-SFL

\section{Introduction}

The study of the interaction between modality and temporality has always been informed by the insight that these two dimensions are not independent. A primary source for this insight is the fact that the interpretation of modal verbs sometimes appears to be fully determined - or at least severely restricted - by the associated temporal configuration. Thus, (1a) only admits an epistemic construal, conveying an inference of the speaker as to the truth of the prejacent ${ }^{1}$, whereas (1b) excludes such an epistemic construal. This difference correlates with the presence of perfect morphology below the modal in (1a) and with the presence of future morphology above the semimodal in (1b):

\section{(1) a. He must have left early. \\ b. He'll have to leave early.}

As for the exclusion of an epistemic construal for (1b), syntacticians have traditionally assumed that "epistemic" modals cannot be dominated by past or future tenses (see for instance Cinque 1999), while acknowledging that this constraint holds at the interpretive, but not necessarily at the overt morphosyntactic level (Stowell 2004). The interpretive constraint finds its semantic rationale in the fact that epistemic construals, which convey that the truth of the prejacent is compatible with or inferable from the beliefs of an epistemic agent (normally the speaker), are indexical in nature (Papafragou 2005), so that the time of modal evaluation is necessarily set to the now of the epistemic agent (Boogaart 2005). Tense on the modal in (1b) sets the time

*I gratefully acknowledge support from the Fédération TUL (FRE 2559 CNRS) for the research program TEMPTYPAC.

Abbreviations: $\mathrm{COND}=$ conditional, $\mathrm{FUT}=$ future, $\mathrm{IMPF}=$ imperfect $/$ imperfective past, $\mathrm{PP}=$ past participle, $\mathrm{PRES}=$ present, $\mathrm{SP}=$ simple (perfective) past. Perfect forms are rendered by the combination of have and the past participle.

${ }^{1}$ I'll follow von Fintel (2005) and von Fintel \& Iatridou (2008) in calling "prejacent" the proposition embedded under the modal. 
of modal evaluation in the speaker's future, and thus precludes an epistemic construal.

The fully determined epistemic construal of (1a), in its turn, can be derived from the combined action of a model restricting the interaction of time with the structure of possibilities and a felicity condition on eligible modal bases. The model of historical necessity captures the intuitive asymmetry between a fixed past and an open future by ensuring that facts that precede or are simultaneous with a time $t$ have no alternatives from the point of view of $t$, though they may have had from the point of view of a previous time $t$ ' with regard to which they were future (Condoravdi 2001, Copley 2002, Kaufmann 2005, Kaufmann, Condoravdi \& Harizanov 2006, Werner 2003, see also Steedman 1997 and Thomason 1984). That is to say, if we are now in a $p$-world on account of past or present facts that have settled the issue, no $\neg p$-worlds are metaphysically acessible from now; because they are settled, past and present facts have no metaphysical alternatives. The diversity condition on the interpretation of modal statements requires that modals applied to a prejacent $p$ be interpreted against the background of modal bases that are diverse as to $p$, i.e. that contain both $p$ and $\neg p$-worlds (Condoravdi 2001, Werner 2003) ${ }^{2}$.

The temporal configuration in (1a) presents the issue of John having left early or not as settled at the time from which the modal base is accessed (which in this example coincides with the time of utterance). This being so, accessible metaphysical modal bases are non-diverse (they contain either only worlds in which he left early, or only worlds in which he did not) and do not qualify as a felicitous background for interpretation. However, by far not every settled fact also happens to be known by an epistemic agent. From the point of view of an agent who does not know which way things went, an epistemic modal base contains the alternatives required by the diversity condition. The epistemic uncertainty construal of (1a) is thus a consequence of the fact that in such a temporal configuration, only epistemic modal bases fulfill the diversity condition.

\footnotetext{
${ }^{2}$ The idea that modal statements involving possibility are subject to such a felicity condition has been around for some time. In fact, Condoravdi (2001: 25) -unlike Werner (2003)- restricts it explicitly to possibility modals. It is obvious that for this condition to be extended to necessity modals, modal quantification has to be further restricted to the "best worlds" as determined by an ordering source (since directly applying universal quantification to a diverse modal base would result in a contradiction). The diversity condition thus only makes sense in a framework that distinguishes between modal bases and ordering sources (see Kratzer 1981, Kaufmann, Condoravdi \& Harizanov 2006). Let me further suggest that the diversity condition is highly reminiscent of the ban against singleton sets as restrictors of quantification, which is well attested in other realms of grammar (\#Every mother of John's is kind, \#When Peter dies, there's sometimes a commotion).
} 
As convincingly shown by Werner (2003), the generalisation according to which modal statements about non-future facts are interpreted against the background of epistemic or subjective uncertainty holds for a large number of environments (see also Kaufmann 2005). It thus seems to capture a central feature of natural modal reasoning.

However, so-called "subjunctive" or "past" modals in English apparently give rise to an ambiguity when they appear in contexts like (1a). As shown by its possible continuations, (2) differs from (1a) in being not only compatible with a construal of epistemic uncertainty (3a), but also with a counterfactual construal, conveying the speaker's belief in the falsity of the prejacent (3b):

(2) He should have left early.

(3) a. Let's check if he in fact did.

b. But he didn't.

In her thorough dissection of the temporal interpretation of English modals, Condoravdi (2001) proposes an analysis of the counterfactual construal for (2) in which the temporal configuration is affected by the additional morphology on the modal, albeit in a quite indirect way. In this analysis, "subjunctive" modals allow for a scope reversal mechanism I will label "covert perfect raising", by which the perfect operator takes scope over the modal. This mechanism has the effect of backward-shifting the time from which the modal base is accessed, thus widening the domain of quantification for the modal to include metaphysical alternatives that, at the time of utterance, may have been discarded by the course of events. Widening the domain triggers the implicature that the speaker does not believe $p$ to be a current possibility at the time of utterance. The two different construals of (2) are thus claimed to be associated with a genuine ambiguity in the temporal configuration involved:

$$
\begin{aligned}
& \text { a. } \text { MOD }>\text { PERF [epistemic construal] } \\
& \text { b. } \text { PERF }>\text { MOD [counterfactual construal] }
\end{aligned}
$$

My aim in this paper is to explore the interactions between temporal configuration and modal interpretation by looking at two Romance languages, French and Spanish. French and Spanish modals exhibit wider and more transparent morphological options than English modals, and their patterns of interpretation diverge in significant ways. This description will show that mere backward-shifting of the time of the modal is not sufficient for conveying a counterfactuality implicature, but that additional aspectual ingredients are required, and will call into question the hypothesis that the 
two different construals of (2) involve a genuine ambiguity, temporal or otherwise $^{3}$

The paper is organised as follows. In section 2 , I will clarify the notion of temporal configuration in a modal environment by resorting to the distinction between temporal perspective and temporal orientation drawn in Condoravdi (2001). I will dwell at some length on the way in which temporal orientation is determined by the aspect of the described situation, in an effort to bring out its pervasive effects. I will also suggest that, over and above the time of modal evaluation and the time of the event, we need to take a third time into account, which I will call "time of decidedness", 4 when assessing statements involving scheduled or foreclosed events. Section 3 is devoted to French modals and past morphology, and shows that backward-shifting of the time of the modal does not produce counterfactual construals in this language. It also provides clear evidence for a scope inversion mechanism by which tense-aspect morphology on a modal may originate and be interpreted below the modal, affecting the prejacent itself. Section 4 examines modals and conditional morphology in French and Spanish. The patterns of interpretation for sequences combining a modal verb in the conditional with perfect morphology, though differing in both languages, are entirely unexpected under Condoravdi's account. Section 5 is devoted to Spanish modals and past morphology. Spanish differs quite spectacularly from French in allowing counterfactual construals for past modals, but these construals require either perfective aspect on the modal, or perfect morphology on the infinitive, or both. I will take this fact as an indication that backward-shifting of the time of the modal only conveys counterfactuality if the issue is taken to be decided at utterance time UTT-T. Section 6 summarizes the results.

\section{Temporal perspective, temporal orientation and decidedness}

Temporal configurations in modal environments involve at least two times: the time from which the modal background is accessed and the time of which

\footnotetext{
${ }^{3}$ Demirdache \& Uribe-Etxebarría $(2006,2008)$ propose an analysis for the English modals that has the clear advantage of motivating the "covert perfect raising" mechanism postulated by Condoravdi. This analysis rests on the assumptions (a) that MOD-T is an interval that cannot be closed, (b) that syntactic movement can intervene to "rescue" a nonsensical temporal configuration, (c) that temporal arguments are syntactic objects that can undergo movement.

4 "Decidedness" is the term proposed by Kaufmann (2005) in order to avoid the potential confusion that may arise from using "settledness" in two different senses, namely settledness of $p$, which is equivalent to truth of $p$ for past, present, and predetermined future facts, and settledness of the issue whether $p$ or $\neg p$. I will try to stick to the convention of referring to the latter as "decidedness" throughout the text.
} 
the temporal property expressed in the prejacent is to hold. As stated above, differences in the location of the former can have direct consequences on the domain of metaphysical possibilities, since possibilities decrease with the course of events (what is settled at a time $t$, and has therefore no metaphysical alternatives from the point of view of $t$, may have had such alternatives at a previous time $t$, , when the issue was not yet decided). Differences in the location of the latter also have direct consequences on the domain of metaphysical possibilities, on account of the settledness of past and present facts. The notion of temporal perspective is designed to locate the time from which the modal background is accessed (henceforth MOD-T), whereas temporal orientation takes care of the time at which the temporal property (the described eventuality) is instantiated (henceforth EV-T).

In extensional contexts, the anchor for the temporal perspective can be safely assumed to be the time of utterance (henceforth UTT-T). In intensional contexts involving an attitude-bearer, the anchor for the temporal perspective is the now of the attitude-bearer. This assumption will prove particularly relevant for the interpretation of modals bearing past morphology in (free) indirect speech or reported thought contexts. Temporal perspective (the ordering of MOD-T with regard to its anchor) is determined by tense. In Condoravdi's proposal, modals can only appear in the scope of present or zero tense. Their temporal perspective is thus uniformly simultaneous to their anchor ("present"), unless the backward-shifting mechanism of "covert perfect raising" (with "subjunctive" modals for the past) ensures a "past" temporal perspective. Thus, both (5a) and (5b) can only have a "present" temporal perspective, (5a) because of the lack of perfect morphology, (5b) because of the lack of the required "subjunctive" morphology enabling "covert perfect raising". Only (5c) allows for an interpretation (the counterfactual construal) for which a "past" temporal perspective is assumed:

$$
\begin{aligned}
& \text { a. He should leave early. } \\
& \text { b. He must have left early. } \\
& \text { c. He should have left early. }
\end{aligned}
$$

As for temporal orientation, a recurrent observation in the literature is that the aspectual class of the described situation determines temporal orientation. In English, eventive predicates uniformly receive a forwardshifted, "future" orientation (6a), whereas stative predicates receive by default a simultaneous, "present" orientation (6b) and are compatible with a "future" orientation in the presence of future-oriented adverbials (6c):

(6) a. John may get drunk/ talk with the Dean.

b. John may be drunk. 
c. John may be drunk by the time we arrive.

The progressives of eventive predicates behave like states, with a default "present" orientation (7a) that can be overriden by a future-oriented adverbial (7b):

(7) a. John may be getting drunk/ talking with the Dean.

b. John may be getting drunk/ talking with the Dean by the time we arrive.

In Condoravdi's framework, perfect infinitives determine a "past" orientation. Note, however, that if one adopts the view that perfect infinitives contribute the post-state of an event (see Kamp \& Reyle 1993 among many others), the facts are entirely parallel to those for states and progressives, with a default "present" orientation for the post-state (8a) that can be overriden by a future-oriented adverbial in a "future perfect" configuration (8b):

(8) a. John may have gotten drunk/ talked to the Dean.

b. John may have gotten drunk/ talked to the Dean by the time we arrive.

Condoravdi's analysis accounts for the obligatory "future" orientation of eventives and the "present" or "future" orientation of states by assuming that modals uniformly expand the time of evaluation forward. MOD-T is modelled as an open interval [t, _) stretching indefinitely into the future of $t$. The initial boundary of MOD-T is set by the temporal perspective. In examples (6-8) this initial boundary can, for the reasons explained above, only be present (simultaneous with UTT-T). The open interval is required to include $\mathbf{E V}-\mathbf{T}$ in the case of eventive predicates (so that the first moment of EV-T cannot precede the first moment of MOD-T), but only to overlap with it in the case of stative predicates (thus allowing, but not forcing, a reading in which the first moment of EV-T precedes the first moment of MOD-T). The perfect, in Condoravdi's analysis, contributes an anteriority relation which takes the initial boundary of MOD-T as anchor and thus ensures a "past" orientation.

The pattern of temporal orientation according to which eventives determine a "future" orientation and states a "present" one is pervasive in English. As shown by Iatridou (2000) and Kaufmann (2005), it also holds for the present and "fake past" ("subjunctive") antecedents of conditionals, which constitute modal environments and are standardly analyzed as containing a covert modal operator. However, the same pattern can also be recognised in simple present sentences, in which no obvious element in the context introduces modality, and even in infinitival complements of attitude 
verbs requiring simultaneous readings (the class labelled B-verbs in Abusch 2004). In fact, whereas states in the simple present or as infinitival complements of B-verbs have a "present" orientation (9a-b), eventives have a "future" one -- unless they can be interpreted generically/habitually 5 . Future-oriented eventives give rise in such contexts to so-called scheduled interpretations (Copley 2008, Kaufmann 2005, Kaufmann, Condoravdi \& Harizanov 2006). As a consequence, only events that are amenable to scheduling can naturally occur therein, as shown by the differences in acceptability between (10a-b) and (11a-b):

a. John is sick.

b. John is said to be sick.

(10) a. ??John gets well.

b. ??John is said to get well.

a. Our train leaves from platform $\mathrm{C}$.

b. Our train is said to leave from platform C.

The hypothesis that MOD-T is a forward-expanding open interval $[\mathbf{t}, \ldots$ ) is posited as a means of capturing the influence of aspectual class on temporal orientation. However, it fails to account for temporal orientation in two crucial points. Firstly, the future orientation of eventives also holds outside modal environments. The "futurate" interpretation of eventive infinitives embedded under B-verbs provides clear evidence that this property is independent of the embedding context. B-verbs actually require simultaneity of the infinitival complement with the reported attitude (Abusch 2004), but the time of instantiation of an eventive infinitive is no less forward-shifted in these contexts than it is in the context of an embedding modal. Secondly, as recently observed by Copley (2008), the assumption that states are required to overlap with MOD-T does not explain why states do not shift forward freely, but are normally interpreted as "present" in the absence of a future anchor they could be simultaneous to. In fact, the futureoriented adverbial in example (6c), as well as those in (7b) and (8b), are essential for the future-orientation of a state.

As emphasized by Copley (2008), the correlation of aspectual class with temporal orientation takes the form in (12a-b), and is thus actually stronger than predicted in Condoravdi's analysis:

a. EVENTIVES $\rightarrow$ "FUTURE" ORIENTATION

b. STATES $\rightarrow$ “PRESENT” ORIENTATION

\footnotetext{
${ }^{5}$ Following Smith (1991), I assume that generic/habitual interpretations constitute derived stative situations. Their temporal orientation is thus predictably "present".
} 
Conceiving of MOD-T as a forward expanding open interval [t, $]$ helps capture the fact that temporal orientation is NON-PAST in modal environments, but it does not contribute much to explain the correlation in (12). The crucial question concerning temporal orientation is why states are simultaneous to the initial boundary of MOD-T (the time from which the modal base is accessed) if nothing else intervenes, whereas eventives cannot be simultaneous, but only follow it.

Phenomena of aspectual-class driven temporal location involving a difference between states and eventives have been extensively explored both in discourse (see for instance Kamp \& Reyle 1993) and in the study of tenseless languages (see Smith 2008). The general simultaneity requirement for states can be derived from a crucial property of their temporal structure: they are totally homogeneous situations, lacking endpoints. Since their initial or final transitions are not part of their temporal structure (Smith 1991), they are not available for temporal location. Furthermore, because of their temporal homogeneity, states can be evaluated at points in time (Dowty 1979). As a result, states will have a default "present" orientation. Eventives, by contrast, are not totally homogeneous and their temporal structure has endpoints. Since they involve change, they cannot be evaluated at points in time (Dowty 1979). This is the source of the Bounded Event Constraint, which excludes a "present" orientation for eventives (Smith 2008). In a NON-PAST environment, such as is contributed by a modal verb, but also by the present tense in (11a) or by the attitude verb in (11b), the only available possibility for eventives is thus "future" orientation.

In English, the Bounded Event Constraint holds for all nonaspectualised eventives, unless they can be understood as habituals/generics, i.e. as derived states. Eventives in the progressive (cf. (7a-b) above) behave as states. Whether the progressive is interpreted as changing the temporal structure of the eventuality by providing a derived state, or as the expression of a viewpoint aspect excluding the initial and final endpoints of the eventuality, while entailing their initial transition (Smith 1991), the resulting structure is the same: a lack of endpoints that will result in a default "present" orientation. The same reasoning can be extended to perfect infinitives (cf. 8a $-b)$ above), if they are held to contribute the post-state of an eventuality: the post-state will have a default "present" orientation, and the described eventuality will, as a consequence, strictly precede the anchor.

The pattern in (12a-b) is also detectable in Spanish and French, but with one significant difference. The temporal orientation of states is, as in English, by default "present", and the temporal orientation of achievements is uniformly "future". But it seems possible, and much easier in French than in Spanish, to get a "present" orientation for atelic eventive predicates, such as activities (and those accomplishments that might be reinterpreted as activities). This is illustrated in (13a-b) and (14a-b) by the contrast between 
'destroy the evidence', an accomplishment that is not easily coerced into an activity, and the activity predicate 'talk to the Dean':

(13) French

a. Il doit détruire les preuves.

He MUST.PRES destroy the evidence

'He must destroy the evidence'

b. Il doit s'entretenir avec le Doyen.

He MUST.PRES talk to the Dean

'He must talk to the Dean'/ 'He must be talking to the Dean'

(14) Spanish

a. Debe destruir las pruebas.

MUST.PRES.3.SG destroy the evidence

'S/he must destroy the evidence'

b. Debe conversar con el Decano.

MUST.PRES.3.SG talk to the Dean

'S/he must talk to the Dean'/ ??'S/he must be talking to the Dean'

As indicated by the glosses, the telic predicates in (13a) and (14a) only give rise to a future-oriented interpretation. By contrast, the atelic predicate in (13b) can also give rise in French to a present-oriented interpretation, thus conveying an inference of the speaker as to a settled present fact (epistemic uncertainty reading). This interpretation is much less natural in Spanish. This peculiarity in the possible temporal orientation of atelic eventives extends to the other contexts mentioned above, most notably to the present and "fake past" ("subjunctive") antecedents of conditionals, to simple present sentences, and to infinitival complements of B-verbs. The pattern observed for French and Spanish is summarized in (15):

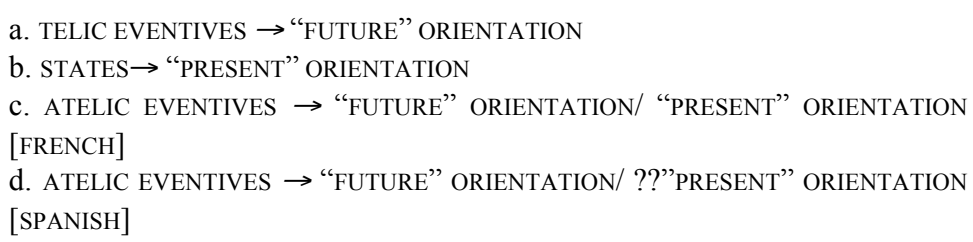

The different patterns exhibited by English, Spanish, and French clearly correlate with the availability and "obligatorification" of a progressive form and with its effects on simple (non-progressive) forms. English has a fully grammaticalised progressive and therefore does not normally allow ongoing readings for the simple forms of eventive predicates. The progressive in Spanish is more widely available than it is in French (for the dubious status of être en train de + Infinitive in French, see Smith 1991, for a comparison between French and Spanish, see Bertinetto 2000). Though not 
entirely excluded, ongoing readings for non-progressive forms are difficult to obtain in Spanish (see Laca 2005a). The question of the "obligatorification" of a progressive form - as a function of its polarization effects on simple (non-progressive) forms -- is notoriously complex, and cannot be explored in this paper. But it is important to note that the patterns of temporal orientation in (12) and (15) correspond to quite general patterns of .aspectual-class driven temporal location for forms lacking explicit temporal or aspectual morphology, which are known to be sensitive to the availability and obligatoriness of contrasting forms (see Smith 2008). What seems to be at work in temporal orientation is a strategy for ordering the temporal trace of an eventuality relatively to a point in time when strict anteriority is not an option and no aspectual morphology further specifies the relation ${ }^{6}$. For the complement of modal verbs, this anchoring point is the initial boundary of MOD-T.

Recall now that temporal perspective, as determined by tense, orders the initial boundary of MOD-T with regard to UTT-T, and that temporal orientation, as determined by aspectual class, is the location of EV-T with regard to the initial boundary of MOD-T. Thus, there is no direct relation linking EV-T with UTT-T. The question that arises at this point is whether temporal perspective and temporal orientation capture all the relevant aspects of temporal configurations in modal environments. The assessment of modal statements involving scheduled or foreclosed events suggests that this is not the case.

As discussed in the introduction, modal statements about decided issues are interpreted against the background of epistemic or subjective uncertainty as a way of fulfilling the diversity requirement for the modal base. If an issue is not yet decided, objective uncertainty obtains and ensures diversity for a metaphysical or circumstantial modal base. Of course, objective uncertainty invariably gives rise to subjective uncertainty (for a formalisation of this fact, see the lack-of-foreknowledge principle in Kaufmann, Condoravdi \& Harizanov 2006). But the readings that are normally recognised as "epistemic" readings for modals, those that convey that the truth of the prejacent is compatible with or inferrable from the beliefs of a speaker who does not know for sure, are those involving epistemic uncertainty about decided facts. Decidedness of the issue (objective

\footnotetext{
${ }^{6}$ In the solution proposed by Demirdache \& Uribe-Etxebarria $(2006,2008)$, the voidness of the aspectual head which should determine the relationship between Ev-T and Ast-T (the interval for which the assertion is made, which corresponds to Smith's 1991 "interval of visibility") plays a crucial role in temporal orientation. I cannot discuss their solution here, but I believe that the basic intuition is the same as the one suggested in the text, namely that the problem of temporal orientation is a possible ramification of the much larger problem of "unspecified" aspect.
} 
certainty) is a necessary condition for epistemic readings. The problem is that, as discussed in Condoravdi (2001), we sometimes obtain "epistemic" readings in connection with future orientation. The example proposed by Condoravdi is revealing:

(16) He will meet with one senior administrator. It has been decided who he will meet but I don't know who it is. He may see the dean. He may see the provost.

Epistemic readings for modals embedding future oriented eventives involve scheduled or pre-determined events (Copley 2008). Although EV-T is in the future, there are present relevant facts (the existence of a plan determining who he is supposed to see in (16) above) that are held to entirely determine at UTT-T the truth-value of the corresponding "futurate" prejacent. Such cases are thus instances of deterministic or "check the facts"-futures, as opposed to indeterministic or "wait-and-see" futures (see Bonomi \& Del Prete 2008). Temporal perspective and temporal orientation do not exhaust all the relevant aspects of this temporal configuration. Crucially, we need to capture the fact that the prejacent, notwithstanding the future orientation of the eventive predicate, has a knowable truth value at UTT-T. I propose to capture this fact by assuming a relationship directly linking the "time of decidedness" to UTT-T. Schematically, the configuration corresponding to He may see the dean in the above context can be represented as in (17):

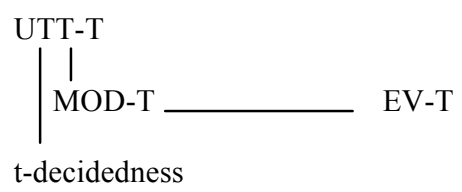

A second motivation for the necessity of dissociating a "time of decidedness" from temporal orientation is provided by temporal mismatches giving rise to counterfactual readings, as exemplified in (18):

Laure might have won tomorrow's race.

Such examples present the eventuality described in the prejacent as foreclosed by the intervention of some event precluding its occurrence. The temporal adverbial clearly locates EV-T in the future of UTT-T. In Condoravdi's analysis, the mechanism of covert perfect raising would determine a past temporal perspective, and the eventive infinitive (not affected by the perfect) a future temporal orientation. As far as I can see, this temporal configuration fails to capture a non-cancellable feature of (18), 
namely that, at UTT-T, the issue of Laure's winning or not tomorrow's race is already decided. At a more general level, genuine counterfactuality presupposes decidedness at UTT-T, and it is not easy to see how the combination of a past temporal perspective with a future orientation is apt to convey decidedness. As we will see in the next sections, a past temporal perspective is clearly not sufficient for conveying counterfactuality, and the analysis of counterfactual readings in terms of covert perfect raising poses serious problems in French and Spanish alike. This will lead us to abandon the idea that the contribution of perfect morphology to counterfactuality consists in setting back the time from which the modal base is accessed. On the contrary, I will propose that perfect morphology directly links the "time of decidedness" to UTT-T ${ }^{7}$.

\section{French modals and past morphology}

By contrast with English modals, French modals can be fully and transparently inflected and thus bear past morphology. Past morphology on a modal does not always determine a past temporal perspective, but even in the cases where it does, it never warrants a counterfactual construal, thus calling into question the assumption that past temporal perspective is the factor that triggers counterfactual construals.

Let us first review the possible interpretations of sequences containing modals in the Passé composé, which we will treat, with some degree of simplification, as an expression for a perfective past. Such sequences admit two interpretations: (a) an entailing interpretation, in which there is a clear inference that the eventuality took place in the actual world, and (b) an epistemic interpretation, in which the past occurrence of the eventuality is inferred or conjectured against the background of subjective epistemic uncertainty. The sequences exclude a continuation in which nonoccurrence of the eventuality is asserted, i.e. they are not compatible with counterfactuality:

$$
\begin{aligned}
& \text { a. Pierre a pu prendre le train de 3.50, [\#mais il ne l'a pas fait]. } \\
& \text { Pierre has CAN.pP take the train of } 3.50 \text {, [\#but he didn't] } \\
& \text { \#'Pierre managed to take the } 3.50 \text { train, but he didn't' } \\
& \text { \#'Pierre may have taken the } 3.50 \text { train, but he didn't' } \\
& \text { b. Pierre a dî payer une amende importante, [\#mais il ne l'a pas }
\end{aligned}
$$

\footnotetext{
${ }^{7}$ Locating the 'time of decidedness' before UTT-T is crucial in the case of some configurations giving rise to non-cancellable counterfactual implicatures, such as temporally mismatched sentences with future adverbials (see above) and statives in the perfect with present oriented adverbials, as in He should/could have been in his office by now.
} 
fait].

Pierre has MUST.pp pay a fine important, [\#but he didn't]

\#'Pierre was forced to pay a huge fine, but he didn't'

\#'Pierre must have paid a huge fine, but he didn't'

I will not dwell further on the entailing interpretation, which has been extensively analyzed by Hacquard (2006). I agree in principle with her idea that such interpretations involve a lower modal under the scope of tense and aspect (see also Borgonovo \& Cummins 2007) ${ }^{8}$.

If morphology is taken at face value, the epistemic interpretation of (19a-b) poses two related problems. Firstly, it clashes with the assumption that telic eventive infinitives, since they give rise to future orientation according to the pattern in (15a), cannot convey the decidedness required by epistemic interpretations in the absence of explicit contextual clues. Secondly, it apparently violates the constraint according to which, in epistemic interpretations conveying inferences and conjectures, the time of modal evaluation coincides with the now of the epistemic agent. The fact is, however, that in such cases overt morphology does not seem to be a reliable guide to interpretation.

There is a widespread consensus that these configurations involve scope inversion between the modal and tense-aspect morphology (Stowell 2004, Borgonovo \& Cummins 2007, Demirdache \& Uribe-Etxeberria 2006, 2008, Hacquard 2006). As suggested by the glosses, the epistemic interpretation of (19a-b) does not exhibit a past temporal perspective with a future orientation, but rather a present temporal perspective with a past orientation. For all practical purposes, (19a-b) are equivalent to the more transparent linearisations in $(20 \mathrm{a}-\mathrm{b})$ :

a. Pierre peut avoir pris le train de 3.50 .

Pierre CAN.pREs have take.pP the train of 3.50

'Pierre may have taken the 3.50 train'

b. Pierre doit avoir payé une amende importante.

\footnotetext{
${ }^{8}$ Let me observe, however, that entailing interpretations are always related to the intentions or desires of an agent, which may either overcome or be thwarted by opposing forces. It is not clear to me how Hacquard's analysis can capture this fact. In any case, the entailing interpretation seems to vanish whenever the described eventuality is not of the kind that can be intentionally brought about or prevented by an agent, so that (i) and (ii) only have the epistemic interpretation:

(i) Il a pu pleuvoir.

It has CAN.pp rain 'It may have rained'

(ii) Pierrea dî trébucher.

Pierre has MUST.pP stumble 'Pierre must have stumbled'
} 
Pierre MUST.PRES have pay.pP a fine important

'Pierre must have paid a huge fine'

As pointed out by Stowell (2004), possible syntactic accounts for scope inversion all come at a certain cost. The less costly solution appears to be a reconstruction-like analysis in which tense-aspect morphology originates between the modal and the verbal projection and raises to combine with the modal, while being interpreted in its original position, as schematically represented in $(21)^{9}$ :

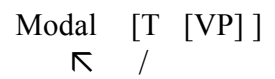

But even though being less costly, reconstruction-like analyses should be motivated by stronger evidence than simple semantic intuition. As far as I can see, the strongest empirical support for this analysis comes from an observation formulated originally by Tasmowski $(1980)^{10}$ : the choice of past morphology appearing on the modal in an epistemic interpretation matches exactly the choice that would be mandatory for the main verb of the prejacent in the absence of the modal. Such mandatory choices for a Passé composé, for an Imparfait and for a Plus-que-parfait are illustrated below. They are determined by the aspectual class of the described situation and by the temporal adverbial in (22a-b), and additionally by overall temporal coherence in a sequence like (23a):

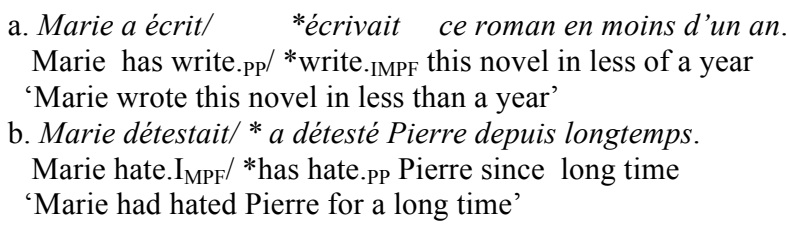

$$
\text { a. Pierre partit de Londres un jeudi. Il y était arrivé la veille. }
$$

\footnotetext{
${ }^{9}$ See however Demirdache \& Uribe-Etxeberria (2008) for an alternative solution, proposed for Spanish, in terms of lowering of a temporal head expressing anteriority to a void aspectual head below the modal. This movement is semantically motivated by the need to avoid an uninterpretable temporal configuration. I cannot dwell on the details of their analysis, but I suspect that configurations with pluperfect morphology above the modal, as in (26a) below, are not amenable to this solution in their framework, since we have a second anteriority relation that must be expressed somewhere.

${ }^{10}$ See Borgonovo \& Cummins (2008) for additional evidence.
} 
Pierre partir.SP of London a Thursday. He there be.IMPF arrive.pP the daybefore

'Pierre left London on a Thursday. He had arrived there the day before'

b. \#Pierre partit de Londres un jeudi. Il y est arrivé la veille.

Pierre partir.sP of London a Thursday. He there be.pRES arrive.pP the daybefore

$$
\text { Il } y \text { arrivait la veille }
$$

He there arrive. IMPF $_{\text {the day-before }}$

\#'Pierre left London on a Thursday. He has arrived/was arriving there the day before'

The crucial observation is that a past-tense devoir only gets an epistemic (inferential) interpretation if the past morphology replicates this choice:

$$
\begin{aligned}
& \text { a. Marie a dî écrire ce roman en moins d'un an. VEPISTEMIC } \\
& \text { Marie has MUST.pp write this novel in less of a year } \\
& \text { 'Marie must have written this novel in less than a year' } \\
& \text { b. Marie devait écrire ce roman en moins d'un an. *EPISTEMIC } \\
& \text { Marie MUST.IMPF write this novel in less of a year }
\end{aligned}
$$

'Marie was supposed/ had to write this novel in less than a year'

a. Marie devait détester Pierre depuis longtemps.

Marie MUST.IMPF hate Pierre since long time

'Marie must have hated Pierre for a long time'

b. *Marie a dû détester Pierre depuis longtemps.

Marie has MUST.Pp hate Pierre since long time

(26) a. Pierre partit de Londres un jeudi. Il avait dî y arriver.

P. leave.SP of London a Thursday. He have.IMPF MUST.PP there arrive.PP la veille

the day-before

'Pierre left London on a Thursday. He must have arrived there the day before'

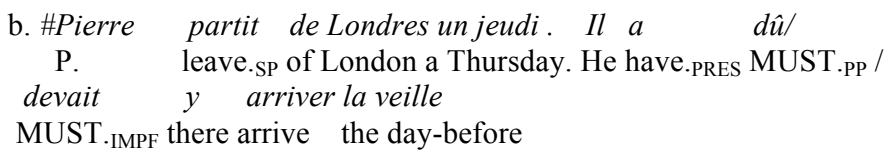

On the basis of this evidence, I will adopt the consensual view that past morphology in the epistemic readings of $(19 a-b)$ does not determine temporal perspective but reflects temporal orientation. Though realized on the modal, past morphology only has scope over the prejacent. This view immediately circumvents the difficulties associated with an epistemic construal (a) whose time of modal evaluation does not coincide with the now of the epistemic agent and (b) which involves eventive infinitives normally determining a future orientation. It should be stressed that adopting this view forces us to assume that there is "inner tense", i.e. tense below the modal, in epistemic readings conveying inferences or conjectures (see Steedman 1997). The central piece of the analysis is overt movement without interpretive 
consequences, a sort of "overt tense-aspect raising" that contrasts with the "covert perfect raising" assumed by Condoravdi (2001) for the counterfactual construal of English modals for the past.

Let me recapitulate the findings up to now. A Passé composé never gives rise to a counterfactual construal. If it originates and is interpreted above the modal, we obtain an entailing interpretation. If it originates and is interpreted below the modal, it conveys a (present) inference or conjecture with regard to a past event. Imparfait and Plus-que-parfait on a modal can also originate and be interpreted below the modal and convey (present) inferences or conjectures with regard to past events.

However, unlike the Passé composé, the Imparfait and the Plus-queparfait on a modal are also compatible with epistemic readings in a different temporal configuration, in which they also fail to determine a past temporal perspective. The Imparfait is known to exhibit both genuine past tense uses and anaphoric or "zero-tense" uses in past intensional contexts. In the latter case, it conveys simultaneity with a past act of thinking or speaking. I will refer to the former as "free" imperfects and to the latter as "bound" imperfects. "Bound" imperfects give rise to epistemic readings of modals bearing past-morphology, as shown in (27a-b). These readings are licensed by the past in the matrix, and disappear in the context of an embedding present tense (28a-b):

a. Le voyantarriver si tôt, j'ai pensé qu'il devait avoirpris le him seeing arrive so early, I thought that he MUST.IMPF have take.PP the premier train. first train

'Seeing him arrive so early, I thought that he must have taken the first train'

b. Tout suggérait que la lettre pouvait avoir été envoyée par un proche. all suggested that the letter CAN.IMPF have been sent by a friend 'Everything suggested that the letter might have been sent by a friend' a. ?? Le voyant arriver si tôt, je pense qu'il devait avoir pris le him seeing arrive so early, I think that he MUST.IMPF have take.PP the premier train. first train

b. ?? Tout suggère que la lettre pouvait avoir été envoyée par un proche. All suggests that the letter CAN.IMPF have been sent by a friend

The mechanism of overt and semantically inert "tense raising" we have just discussed can result in equivalent Plus-que-parfait versions for (27a-b). In fact, (29a-b) and (27a-b) alternate without semantic difference, in the same way in which (19a-b) and (20a-b) above alternate:

a. Le voyant arriver si tôt, j'ai pensé qu'il avait dî prendre him seeing arrive so early, I thought that he have.IMPF MUST.PP take 


\author{
le premier train \\ the first train \\ 'Seeing him arrive so early, I thought that he must have taken the first train' \\ b. Tout suggérait que la lettre avait pu être envoyée par un proche. \\ all suggested that the letter have.IMPF $C A N$.PP been sent by a friend \\ 'Everything suggested that the letter might have been sent by a friend'
}

Epistemic readings with "bound" Imparfaits, which may appear massively in free indirect speech contexts, do not really challenge the constraint according to which epistemic construals are tied to the now of the epistemic agent and thus require a present temporal perspective. In (free) indirect speech or reported thought contexts, the Imparfait is an anaphoric tense, interpreted simultaneously to the now of the attitude bearer: the temporal perspective in these contexts is that of a "present of the past"

This leaves us only "free" Imparfaits as possible candidates for determining a past temporal perspective. The question to be answered at this point is whether a "free" Imparfait determining a past temporal perspective, in combination with an eventive infinitive imposing a future temporal orientation, gives rise to a counterfactual construal (recall that in Condoravdi's analysis, the counterfactual construal is triggered by the combination of a past temporal perspective and a future temporal orientation). Hacquard (2006: 77) gives an affirmative answer to this question, asserting that (30) "is compatible with Jane actually taking the train and going to London, but the preferred reading is that she in fact didn't":

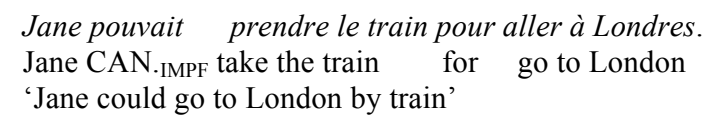

I must disagree with her on this point. I believe that there is a fundamental difference between the counterfactual construal discussed by Condoravdi and the putatively preferred interpretation of (30). A genuine counterfactual construal should be at the very least incompatible with the certainty of the speaker as to the truth of the proposition being evaluated. This is a property that "subjunctive" modals for the past in English have (cf. 31a), but that the configuration in (30) admittedly lacks:

\footnotetext{
${ }^{11}$ Boogaart (2005), though rejecting the "zero-tense" hypothesis, has shown the pervasive presence of epistemic modals bearing past morphology in such contexts. He emphasizes the fact that such epistemic readings require simultaneity of MOD-T with a past act of thinking or speaking that must be overtly expressed or otherwise be clearly inferrable from the context.
} 
(31) a. Jane could have gone to London by train, \#so she did.

b. Jane pouvait prendre le train pour aller à Londres, et c'est ce qu'elle a

fait.

Simple compatibility with - or even preference for- a continuation asserting the falsity of the prejacent is not enough for attributing counterfactuality to an environment. Note, furthermore, that the French configuration in (30) - a good candidate for past temporal perspective and future orientation - differs from the English configuration in (31a) in another important respect. The former is infelicitous in contexts in which the falsity of the prejacent is established, the latter is not:

$$
\begin{aligned}
& \text { a.\# Le patient est mort, bien qu' il pouvait être sauvé. } \\
& \text { The patient has died, although he CAN.IMPF be saved } \\
& \text { \#'The patient died, although he could be saved' } \\
& \text { b. The patient died, although he could have been saved. }
\end{aligned}
$$

On the basis of the compatibility of the Imparfait in (30) with an assertion as to the truth of the prejacent, and of its incompatibility in (32a) with contexts in which its falsity is established, we conclude that "free" Imparfaits no more license counterfactual construals in French than the Passé composé does. The indicative contexts reviewed up to this point show that the simple combination of past temporal perspective with future orientation is not an available strategy for conveying counterfactuality in French. As we will see in the next section, counterfactual readings in French require special morphology on the modal.

\section{Modals and conditional morphology in French and Spanish}

Conditional morphology (Imparfait morphology on a future stem) plays a central role in the expression of counterfactuality, since it typically appears in the consequent of counterfactual or "future-less-vivid" conditionals (Iatridou 2000). If we grant that Romance modals bearing conditional morphology are the nearest equivalent to English "subjunctive" modals (von Fintel \& Iatridou 2008), the pattern in (33a-b) appears to indirectly confirm Condoravdi's analysis of English. As shown by the possible continuation as to the falsity of the prejacent, a counterfactual construal is available when the perfect appears above the modal (33a), but it seems excluded when the perfect appears below the modal (33b):

$$
\begin{aligned}
& \text { a. Marie aurait pu gagner la course (mais elle l'a perdue). } \\
& \text { M. have.COND CAN.PP win the race (but she lost). }
\end{aligned}
$$


'M. might/ could have won the race'

b. Marie pourrait avoir gagné la course (\#mais elle l'a perdue).

M. CAN.COND have win.pp the race (\#but she lost).

'M. possibly/ allegedly/ reportedly won the race'

Note that this pattern, while apparently providing evidence for the link between the $\left[\mathrm{PERF}_{\mathrm{COND}}>\mathrm{MODAL}\right]$ configuration and the counterfactual construal, confirms at the same time that additional morphology on the modal (conditional morphology in French, a "subjunctive" modal in English) is a necessary ingredient for this construal. This fact is not accounted for in Condoravdi's analysis.

Furthemore, upon closer inspection the pattern linking the position of perfect morphology above the modal to counterfactuality, and its position below the modal to epistemic uncertainty, turns out to be less conclusive, and to partially differ for possibility and necessity modals.

In fact, the configuration $\left[\mathrm{PERF}_{\mathrm{COND}}>\mathrm{MODAL}\right]$ in (33a) is not only compatible with counterfactuality, but also with a construal of epistemic uncertainty. This is shown not only by the acceptability of a continuation conveying epistemic uncertainty - pour autant que nous sachions "for all we know" is unobjectionable both after (33a) and after (33b) - but also in naturally occurring examples as $(34 \mathrm{a})$, in which the $\left[\mathrm{PERF}_{\mathrm{COND}}>\mathrm{MODAL}\right]$ configuration with the possibility modal is used for establishing a hypothesis, not for discarding it. (34b) shows that devoir in the [PERF $\left.\mathrm{COND}_{\mathrm{C}}>\mathrm{MODAL}\right]$ configuration is also compatible with a construal of epistemic uncertainty:

a. Au vu du terrain, un hélicoptère aurait bien pu venir de At sight of-the terrain, a helicopter have.COND well CAN.pP arrive from derrière la colline proche sans être entendu. behind the hill nearby without being heard

'Due to the characteristics of the terrain, a helicopter might well have arrived from behind the nearby hill without being heard'

b. Pierre aurait dî arriverchezlui ily a une heure.

P. have.cond MUST.pp arrive at him it there has an hour Appelle-le pour t'assurer qu'il est bien là.

'Pierre should have arrived home an hour ago. Call him up to check if he's in fact there'

Differences between the possibility and the necessity modal arise for the configuration in which the modal appears above the perfect. In $\left[\mathrm{MODAL}_{\mathrm{COND}}>\mathrm{PERF}\right]$ configurations, devoir - but not pouvoir - is accepted (though dispreferred) with continuations conveying counterfactuality (35a), and occurs naturally (though infrequently) in contexts where no epistemic 
uncertainty is involved, but rather the falsity of the prejacent is asserted or otherwise established (35b):

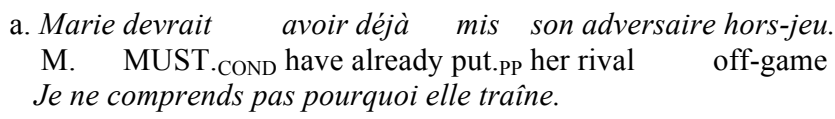

'Marie should have already defeated her rival. I don't understand what she's waiting for'

b. L' ossification est très en retard et sur les radiographies, on note la persistance des cartilages de conjugaison

à un âge où ils devraient avoir disparu.

to an age where they MUST.COND have disappear.PP

'Ossification lags considerably behind and on the X-rays, we see articular cartilages subsisting at an age when they should have disappeared'

The data are extraordinarily complex, but they clearly call into question the assumption of a contrast between a construal of epistemic uncertainty and a counterfactual construal that correlates with a difference in both temporal perspective and temporal orientation. The ambiguity between both construals resurfaces at least in part in French, a language that has the syntactic patterns required to resolve it, and the patterns of ambiguity are sensitive to the quantificational force of the modal. As we will presently see, the Spanish facts, though diverging from what we have just seen for French, reinforce these misgivings.

The first surprising observation is that, although in Spanish, as in French, perfect morphology can be realised either above or below a modal bearing conditional morphology, the pattern of interpretation for the latter case ([MOD. COND $>$ PERF]) is parallel to the English, and not to the French pattern. Crucially, sequences of this type are compatible with counterfactual continuations, and are also perfectly natural in contexts in which the falsity of the prejacent is established. We saw above that this was only marginally possible for devoir in French (see 35a-b above). In Spanish, by contrast, this is the preferred option both for possibility and for necessity modals:

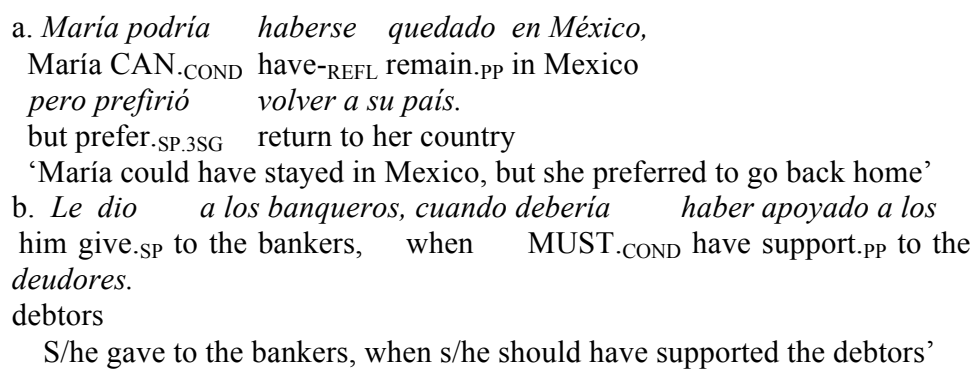

$\mathrm{S} /$ he gave to the bankers, when s/he should have supported the debtors' 
c. En vez de quedarse callado, tendria que haber intervenido. in time of keep-REFL quiet, HAVE.COND that have intervene.pP 'Instead of keeping quiet, s/he should have intervened'

The configuration [ $\left.\mathrm{MOD}_{\mathrm{COND}}>\mathrm{PERF}\right]$ is also compatible with a construal of epistemic uncertainty, as in French or, for that matter, English:

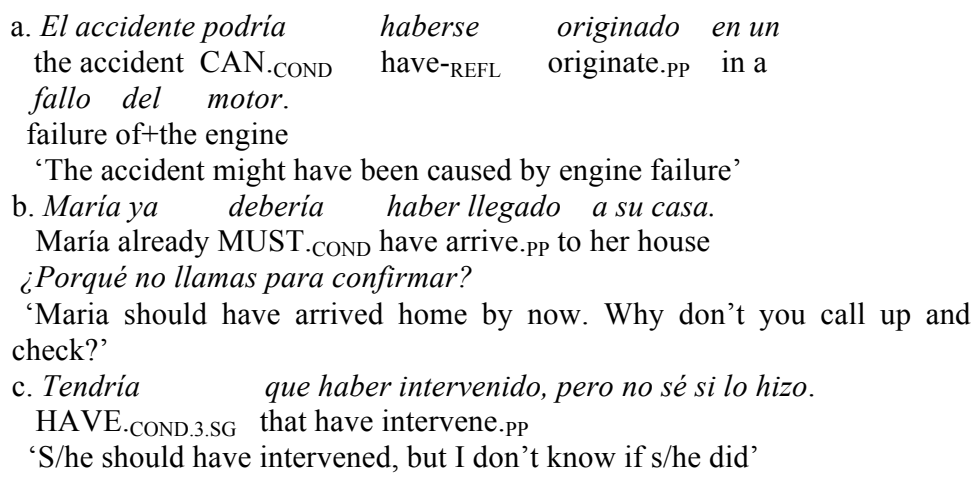

Spanish patterns like French, and unlike English, in admitting constructions in which perfect morphology is realised above the modal. However, $\left[\mathrm{PERF} \mathrm{COND}_{\mathrm{CO}}>\mathrm{MODAL}\right]$ configurations are on the whole less frequent than $\left[\mathrm{MOD}_{\mathrm{COND}}>\mathrm{PERF}\right]$ configurations, and this difference in frequency is much more pronounced in the case of necessity modals ${ }^{12}$. $\left[\mathrm{PERF}_{\mathrm{COND}}>\mathrm{MODAL}\right]$ configurations are fully compatible with counterfactual construals (i.e. the patterns in (36a-c) can be subject to "overt perfect raising" without discernable meaning differences), but epistemic construals seem to be only possible, and marginally so, with the possibility modal. Example (38) parallels the French example (34a) above:

$$
\begin{aligned}
& \text { Por ello, estos cientificos piensan que la primera célula habría } \\
& \text { by this, these scientists think that the first cell have.Cond } \\
& \text { podido viajar protegida dentro de un meteorito desde el planeta en que }
\end{aligned}
$$

\footnotetext{
${ }^{12}$ A search of the Davies corpus (http://www.corpusdelespanol.org) for 20th century Spanish gives the following results:

poder 'can'

deber 'must'

tener que 'have to'

MOD.COND haber V-PP
139
33
22

haber.COND MOD-pP V-INF

63
} 
CAN.pP travel protected inside of a meteorite from the planet in which se originó.

REFL originate.SP

'For this reason, these scientists believe that the first cell might have travelled inside a meteorite from the planet where it originated'

Before proceeding, let us compare our results for French and Spanish. In spite of the complexity of the data, a relatively clear pattern emerges from this comparison. French and Spanish have a linearisation option that is compatible both with a counterfactual construal and with epistemic uncertainty. In French, this option is the configuration in which the perfect appears above the modal, in Spanish it is the configuration in which the perfect appears below the modal. Let us call this the "preferred option" for each language. It is the dispreferred option that appears to lend some support to the assumption of a link between "perfect raising" and

\begin{tabular}{|c|c|c|}
\hline & French & Spanish \\
\hline $\mathrm{MOD}_{\mathrm{COND}}+$ PERF. INF & $\begin{array}{r}\text { VEPIST } \\
\text { CF * pouvoir } \\
(\sqrt{ }) \text { devoir }\end{array}$ & $\sqrt{\mathbb{E} \mathbb{P} \mathbb{S} \mathbb{T}} \quad \sqrt{\mathbb{C F}}$ \\
\hline $\mathrm{PERF}_{\mathrm{COND}} \mathrm{MOD}+\mathrm{INF}$ & $\sqrt{\mathbb{E P I S T}} \quad \sqrt{\mathbb{C} F}$ & $\begin{array}{c}\text { EPIST }(\sqrt{ }) \text { poder } \quad \sqrt{\mathrm{CF}} \\
* \text { deber } \\
\text { *tener que }\end{array}$ \\
\hline
\end{tabular}

Table 1: Possible construals with conditional modals and perfect morphology

counterfactuality, but the support is rather weak. In Spanish a higher perfect precludes epistemic uncertainty with necessity modals, but marginally admits it with the possibility modal; in French, a lower perfect precludes counterfactuality with the possibility modal, but marginally admits it with the necessity modal. The patterns of interpretation are summarized in Table 1 above, in which the preferred option for each language is highlighted.

The patterns of interpretation summarized in Table 1 give rise to a number of related questions:

(i) What is the contribution of conditional morphology?

(ii) Does the difference in the linearisation of perfect morphology reflect a difference in temporal configuration?

(iii) Is there a genuine epistemic/counterfactual ambiguity in contexts involving conditional morphology?

(iv) What accounts for the different behaviour of possibility and necessity modals? 
As to the first question, conditional morphology in French and Spanish is either anaphoric on a past time of thinking or speaking, in its role as "future of the past", or it is licensed by a modal environment. Outside (free) indirect speech or reported thought contexts, conditional morphology appears on modal verbs, on verbs expressing wishes or preferences, and in the consequent of (possibly covert) conditional sentences. In such contexts, conditional morphology acts as a domain-widener: it signals that worlds are being accessed that lie outside the common ground, i.e. outside the domain of what is being taken for granted by the speaker ${ }^{13}$. An indication of the domain-widening effect of conditional morphology is the fact that modals in the conditional are much more easily compatible with negative belief assertions than indicative modals. (39a-b) exemplifies this contrast for the possibility modal in a context of objective uncertainty in Spanish, (40a-b) for the necessity modal in a context of subjective uncertainty in French:

a. ??Puede producirse un accidente, pero no creo que vaya a pasar nada. CAN.PRES produce. REFL $_{\text {an }}$ accident

'There may be an accident, but I don't think anything will happen'

b. Podría producirse un accidente, pero no creo que vaya a pasar nada. CAN. COND produce.REFL an accident

'There might be an accident, but I don't think anything will happen'

a. \#Jean doit être chez lui, mais je ne pense pas qu'il y soit.

Jean MUST.PRES be at home

'Jean must be at home, but I don't think he is'

b. Jean devrait être chez lui, mais je ne pense pas qu'il y soit.

Jean MUST.COND be at home

'Jean should be at home, but I don't think he is'

Note that, in the light of the contribution of conditional morphology in modal contexts, the motivation for backward-shifting MOD-T in order to access metaphysical alternatives discarded by the further course of events is not compelling. If conditional morphology in modal contexts can itself widen the domain of quantification to sets of worlds that do not belong to the common ground, there is simply no need for a second domain widener ${ }^{14}$.

13 On domain-widening by "subjunctive" morphology, see von Fintel (1999) and, for Spanish, Alonso-Ovalle (2002).

${ }^{14}$ Common grounds are modelled as epistemic modal bases (Condoravdi 2001). In the mechanism proposed by Condoravdi (2001), widening the domain of metaphysical alternatives by backward-shifting MOD-T signals that the domain of quantification for the modal is partly outside the common ground. In the present proposal, widening the domain of quantification of the modal to include epistemic alternatives not contained in the common ground (the contribution of conditional morphology) may 
This takes us to our second question: what is the contribution of perfect morphology? A look at what happens in the absence of perfect morphology provides the answer. If the situation described in the prejacent is eventive, and thus determines a "future" temporal orientation, both the epistemic and the counterfactual construal disappear: we obtain weak modal readings involving objective uncertainty.

\author{
French \\ a. Il pourrait rencontrer des difficultés. \\ he CAN.COND meet of +the difficulties \\ 'He could meet with some difficulties' \\ b. Ils devraient aboutir à un accord. \\ they MUST.COND reach to an agreement \\ 'They should reach an agreement' \\ Spanish \\ a. Podría producirse un accidente \\ CAN.COND produce. REFL $_{\text {an accident }}$ \\ 'There might be an accident' \\ b. Deberian llegar a un acuerdo. \\ MUST.COND.3.PL arrive to an agreement \\ 'They should reach an agreement' \\ c. Tendria que tomar el tren de las 3.50 \\ HAVE.COND.3.SG that take the train of the 3.50 \\ 'S/he ought to take the 3.50 train'
}

However, if the situation described in the prejacent is stative, and thus determines a "present" temporal orientation, we obtain both epistemic uncertainty and counterfactual construals, as shown by the two possible continuations in the following examples:

a. Il pourrait être tranquilement chez lui (pour autant que je sache/ au lieu d'étre ici)

'He could be comfortably at home (for all I know/ instead of being here)

b. Ce livre devrait être sur l'étagère de droite

this book MUST.COND be on the shelf of righthand

(va vérifier/ et non pas là où il est)

'This book ought to be on the right-hand shelf (go check/ and not where it is)'
a. Podría
estar tranquilo en su casa
CAN.COND.3.SG be calmly in his house

have the effect of recovering a world history that has been discarded by the course of events. 
(por lo que sél en lugar de estar aqui)

'He could be comfortably at home (for all I know/ instead of being here)'

b. Ese libro deberia estar en el estante de la derecha

this book MUST.COND be in the shelf of righthand

(fijately no donde está)

'This book should be on the right-hand shelf (go check/ and not where it is)'

c. Ese libro tendría que estar en el estante de la derecha

this book HAVE.COND that be in the shelf of righthand

(fijately no donde está)

'This book ought to be on the right-hand shelf (go check/ and not where it is)'

The only difference between (41a-b/42 a-c) above and the examples (43a-b/ $44 \mathrm{a}-\mathrm{c})$ resides in the fact that there is no presumption of decidedness in the former case, but that there is such a presumption in the latter. In fact, the presumption of decidedness is a necessary condition shared by epistemic and counterfactual construals: both require that the issue be settled at UTT-T. In the case of the epistemic construal, the issue is settled, but the speaker does not know in which way it has been settled, in the case of the counterfactual construal, the issue is settled, and the speaker does know in which way. I assume that perfect morphology - whatever its relative position in the preferred option in French or Spanish - contributes this presumption of decidedness, by setting the moment at which $p$ - and $\neg p$-world-histories branch before UTT-T.

In the line of reasoning we are pursuing, the fact that a construction is felicitous both in contexts of epistemic uncertainty as to $p$ and in contexts in which the falsity of $p$ is either established or is to be suggested does not amount to a genuine ambiguity. Conditional modals signal that the domain has been widened to include alternatives that do not belong to the common ground. Perfect morphology signals that the the issue is decided at UTT-T.

The difference between the epistemic and the counterfactual construal hinges on the knowledge attributed to the speaker: counterfactuality arises under the further assumption that the speaker knows which way things went. The difference between both construals thus appears as an instance of the usual jump from "not believing that $p$ is the case" to "believing that $p$ is not the case".

The different behavior of necessity and possibility modals in these configurations is an unexpected result, which requires careful research. I will only advance two remarks which may indicate the direction this research should take.

First of all, note that the patterns in Table 1 can be interpreted in the sense of an affinity of the possibility modal with construals of epistemic uncertainty: pouvoir cannot be associated with the assumption that the 
speaker knows which way things went in the dispreferred configuration in French, and poder can be associated with epistemic uncertainty in the dispreferred configuration in Spanish.

Secondly, though compatible with a construal of epistemic uncertainty, the necessity modal in the conditional is not appropriate in some of the most typical contexts for the epistemic readings of modals. Recall that such readings typically involve an inference or a conjecture of the speaker. Now, necessity modals in the conditional cannot convey inferences as to causes, as shown by the contrasts in (45a-b) and (46a-b):

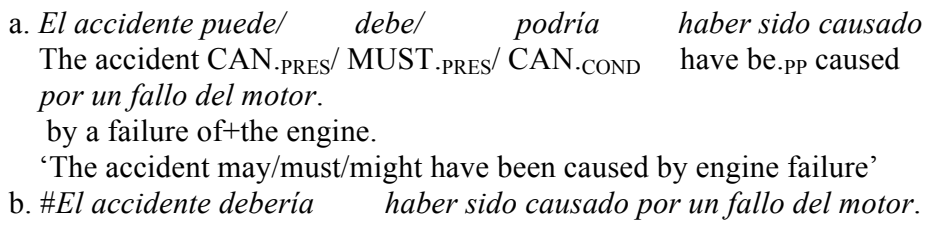

'The accident may/must/might have been caused by engine failure'

b. \#El accidente debería haber sido causado por un fallo del motor.

The accident MUST.COND have be.pP caused by a failure of + the engine

'The accident should have been caused by engine failure'

a. Il y a des traces sur la neige. Les fugitifs

There are traces on the snow. The runaway

ont pu/ ont dul auraient pu empruntercechemin.

have CAN.pP/ have MUST.pP/ have.COND CAN.pP borrow this path.

'There are footprints on the snow. The runaway may/must/might have taken this path'

b.\# Il y a des traces sur la neige. Les fugitifs

There are traces on the snow. The runaway

devraient avoir emprunté ce chemin.

MUST.COND have borrow.pP this path

'There are footprints on the snow. The runaway should have taken this path'

Though compatible with a construal of epistemic uncertainty, necessity modals in the conditional do not seem to give rise to interpretations in which the occurrence of the event is inferable from the information available to the speaker. Rather, they signal that occurrence of the event was expected in the light of previous facts (if everything went as planned or as determined by a previous causal chain). If this intuition is confirmed, it could mean that the preference for epistemic or metaphysical/circumstantial modal bases, rather than being associated to temporal perspective, is associated to modal force.

To summarize, the facts discussed in this section do not validate the hypothesis according to which construals of epistemic uncertainty and counterfactual construals involve a difference in temporal configuration deriving from the scope of the perfect operator. The domain-widening effect stems from conditional morphology, and the perfect operator indicates that the issue has been decided before UTT-T. Rather than with a semantic 
contrast, the linearisation differences correlate with a preference for "higher perfects" in French and for "lower perfects" in Spanish. While modals bearing conditional morphology in French and Spanish do not lend support to the idea that counterfactual construals are determined by a past temporal perspective, we will see in the next section that modals bearing past indicative morphology in Spanish provide such support.

\section{Modals and past morphology in Spanish}

Modals bearing past morphology in Spanish exhibit all the interpretive possibilities we have discussed for French in section 3 . They give rise to entailing readings with the perfective past $(47 \mathrm{a}-\mathrm{b})$, and to epistemic readings in which the morphology on the modal reflects the morphology that would appear in the prejacent (cf. 48a-b and 49a-b):

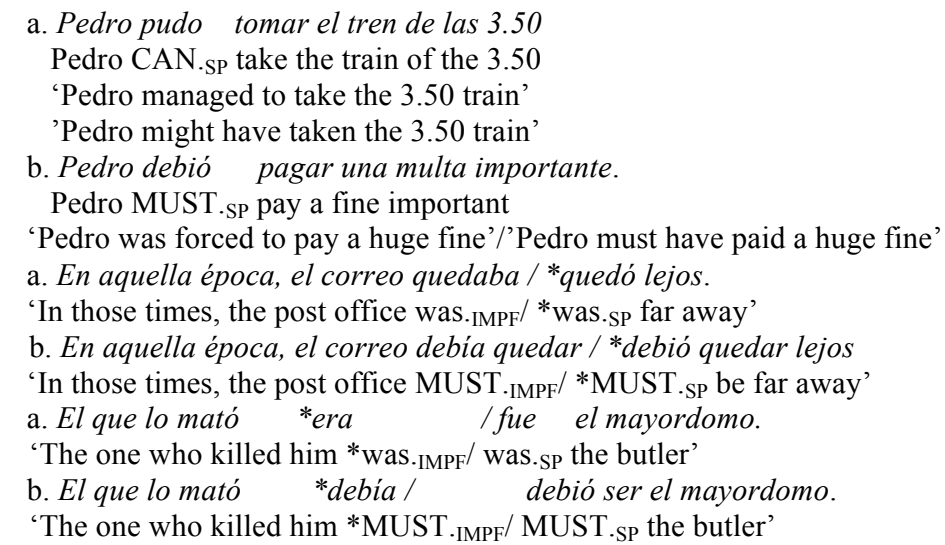

Together with the possibility of epistemic interpretations for (47a-b), the contrasts of acceptability in examples (48b) and (49b) indicate that the same mechanism of "overt tense raising" without interpretive consequences we had assumed for French is also attested in Spanish. A minor, but relevant difference between both languages is that in the case of perfect or pluperfect morphology, Spanish prefers the linearisations with a lower perfect in (50a-b) to the "perfect raised" linearisations in (51a-b). This confirms that Spanish shows a preference for lower, while French shows a preference for higher perfects, as was the case for conditional modals:

$$
\begin{aligned}
& \text { a. Puede haberse producido un accidente. } \\
& \text { CAN.PRES.3.SG. have-REFL produce.PP an accident }
\end{aligned}
$$


'There may have been an accident'

b. Debia haber llovido mucho, porque las calles estaban mojadas. MUST. IMPF.3.SG. have rain.pP a lot, because the streets were.IMPF wet 'It must have rained a lot, because the streets were wet'
a. ?? Ha podido producirse un accidente.
have.PRES.3.SG. CAN.PP produce REFL $_{\text {an }}$ accident
'There may have been an accident'
b. ?? Habia debidollover mucho, porque las calles estaban mojadas. have.IMPF.3.SG MUST.PP rain a lot, because the streets were.IMPF wet
'It must have rained a lot, because the streets were wet'

In any case, the really significant difference is that in Spanish, in contrast with French, past morphology on a modal can give rise to a counterfactual construal. However, counterfactuality only arises in the presence of perfective past morphology on the modal (52), of perfect morphology on the infinitive (53), or of a combination of both (54).

$$
\begin{aligned}
& \text { Maria pudo / debió escaparse (pero no lo hizo) } \\
& \text { María CAN.SP / MUST.SP escape-REFL } \\
& \text { 'María could / should have fleed (but she didn't)' } \\
& \text { María podia / debia/ tenía que haberse escapado } \\
& \text { María CAN.IMPF / MUST.IMPF / HAVE.IMPF +that have-REFL escape } \\
& \text { (pero no lo hizo) } \\
& \text { 'María could / should have fleed (but she didn't)' } \\
& \text { María pudo / debió/ tuvo que haberse escapado (pero no lo hizo) } \\
& \text { María CAN.SP / MUST.SP/HAVE.SP+ that have- REFL escape } \\
& \text { 'María could / should have fleed (but she didn't)' }
\end{aligned}
$$

The possibility of counterfactual construals for (52-54) clearly supports the hypothesis that backward-shifting the time from which the modal base is accessed is a possible domain-widening strategy for conveying counterfactuality. But at the same time, it shows that past temporal perspective and future orientation are not sufficient for the counterfactuality effect: a modal in the imperfective past embedding an eventive infinitive is no more apt to convey counterfactuality in Spanish than it is in French (see the discussion of examples (30-32) above). The question arises at this point as to the necessary ingredient that perfective aspect and/or perfect morphology contribute to the counterfactual construal. I would like to suggest that this is, again, decidedness. Perfective aspect and/or perfect morphology on the infinitive are signaling that $p$ - and $\neg p$-world-histories have branched before UTT-T. 


\begin{tabular}{|c|c|c|}
\hline $\mathrm{MOD}_{\mathrm{SP}}+\mathrm{INF}$ & $\begin{array}{l}\text { TEMPORAL PERSPECTIVE } \\
\text { past }\end{array}$ & $\begin{array}{l}\text { READING } \\
\text { entailing }\end{array}$ \\
\hline & $\begin{array}{l}\text { present ("tense raising") } \\
\text { past }\end{array}$ & $\begin{array}{l}\text { epistemic } \\
\text { counterfactual }\end{array}$ \\
\hline MOD.IMPF $_{\text {IMERF. INF }}$ & $\begin{array}{l}\text { "present of the past' } \\
\text { present ("tense raising") } \\
\text { past }\end{array}$ & $\begin{array}{l}\text { epistemic } \\
\text { epistemic } \\
\text { counterfactual }\end{array}$ \\
\hline 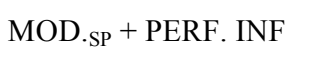 & $\begin{array}{l}\text { present ("tense raising") } \\
\text { past }\end{array}$ & $\begin{array}{l}\text { epistemic } \\
\text { counterfactual }\end{array}$ \\
\hline
\end{tabular}

The above sequences with past modals show multiple ambiguities. Thus, in the absence of the counterfactual continuation, (52) can have an entailing, a counterfactual and an epistemic reading (Borgonovo \& Cummins 2007). Next to its counterfactual reading, (53) can also have en epistemic reading, provided that the imperfect is a "bound" imperfect in a (free) indirect speech or reported thought context (see the discussion of examples (27a-b) above), or that the context licenses a pluperfect prejacent (see the discussion of example (26a) and example (50b) above). Finally, (54) can have both a counterfactual and an epistemic reading. Note that the perfect infinitive in (54), which has been held to be redundant (Bosque 1999), eliminates on the one hand the entailing reading and, on the other hand, is necessary for the counterfactual construal of the possessive modal tener 'have'. These ambiguities correlate with genuine differences in temporal perspective, which are summarized in Table 2 above.

Borgonovo (2008) has recently proposed an analysis in which the three readings for simple past modals in Spanish correlate with different scope configurations among three heads: the modal (MOD), the past tense (PAST) and perfect or perfective aspect (PERF). The three possible scope configurations are given in $(55 \mathrm{a}-\mathrm{c})$ :

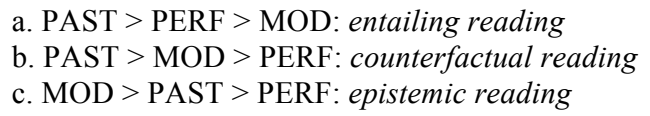

This analysis accounts for the difference between entailing and counterfactual readings, which share a past temporal perspective but differ in the fact that the first embeds a bare infinitive, whereas the second embeds an aspectualised one. It also explains why the perfect infinitive eliminates entailing readings: a perfect infinitive unambiguously signals the presence of aspect below the modal. The configuration attributed to epistemic readings 
corresponds to the source configuration for the mechanism of overt and semantically inert "tense raising" that we have assumed both for Spanish and for French. Finally, the assumption that the Spanish simple past is a complex morphological category, contributing both a tense and an aspect head, squares well with the hypothesis I have defended elsewhere (see Laca 2005a), according to which the Romance simple past is the only simple tense carrying an aspectual specification. I think this analysis is on the right track, although it opens a number of questions as to why and how morphosyntactic configurations involving modals give rise to such peculiar scope permutations $^{15}$.

As to the differences between Spanish, which admits counterfactual readings for past modals under the conditions expressed in Table 2, and French, which doesn't, Borgonovo (2008) suggests that they correlate (a) with the fact that (contemporary informal) French lacks a simple past tense, a suggestion that has also been advanced by Demirdache \& Uribe-Etxeberria (2008), and (b) with the fact that Spanish, unlike French, can use the simple infinitive instead of the perfect infinitive, as shown in (56a-b):

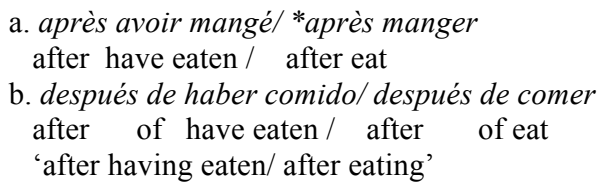

Since French apparently must overtly express perfect on an infinitive, on the one hand, and on the other hand excludes sequences with two perfects, as shown in (57), it lacks the conditions for expressing configuration (55b), which is the source of counterfactual readings with perfective pasts:

$$
\begin{aligned}
& \text { *Elle a pu avoir gagné. } \\
& \text { she has CAN.pP have win.pP }
\end{aligned}
$$

However, these correlations do not explain why modals in the Imparfait in combination with perfect infinitives do not give rise to counterfactual readings in French. Recall that a sentence like (58) can only have an epistemic reading:

\footnotetext{
${ }^{15}$ Note that peculiar scope effects with modals seem to be pervasive. They not only surface in connection with tense and aspect, but also in connection with other operators, as for instance other modals and negation in the can't seem-construction (cf. Jacobson 2006) or subject quantifiers giving rise to "epistemic containment" (von Fintel \& Iatridou 2003).
} 
I surmise that this impossibility correlates with several other differences in the possible range of interpretations for the imperfective past in French and Spanish which cannot be explored in this paper.

\section{Concluding remarks}

In this paper, we have examined the interactions between tense-aspect morphology and the interpretation of modals in French and Spanish in the light of the analysis proposed by Condoravdi (2001) for English. Although we have found evidence both for scope inversion phenomena and for the hypothesis that a past temporal perspective may contribute to counterfactual interpretations, no clear evidence was found for the idea that "perfect raising" contributes to backward-shifting MOD-T and thus to the domain-widening that results in counterfactual readings. Both French and Spanish allow for the surface order PERF $>M O D$, but such configurations only give rise to counterfactual readings in the presence of an extra element of modal-tense morphology, the conditional, which is itself a domain-widener. The preferred linearisation options in such cases, which differ for both languages, are felicitous both in contexts of epistemic uncertainty and in counterfactual contexts, an entirely unexpected fact that calls into question the existence of a genuine epistemic-counterfactual ambiguity with conditional modals -which, we assume, roughly correspond to English "subjunctive" modals. The different behaviour of possibility and necessity modals seems to indicate that necessity modals in the conditional always rely on metaphysical/circumstantial modal bases.

The inability of modals in the imperfective past or in the conditional to trigger counterfactual readings when they embed simple eventive infinitives, together with the possibility of counterfactuality with stative infinitives or in the presence of perfect morphology (modulo some relevant differences between both languages) indicates that a past temporal perspective or domain-widening morphology are not sufficient for counterfactuality. We have hypothesized that the role of perfect morphology is to provide the missing element of decidedness for eventives, by indicating that the relevant branching between $p$ and $\neg p$ world histories has taken place before UTT-T. For statives, decidedness is ensured by the fact that, in the absence of other temporal clues, they will be interpreted as simultaneous with UTT-T.

We have remained agnostic as to the usefulness of conceiving MOD-T as an open interval stretching indefinitely into the future. 
Phenomena of aspectually-driven temporal orientation arise with the same characteristics in contexts not involving modals, and if they are actually governed by the Bounded Event Constraint, they involve temporal location with regard to a point (the initial boundary of MOD-T). On the other hand, we have shown that -if temporal orientation is conceived as the relation between EV-T and MOD-T- we need a third relation directly linking the "time of decidedness" of the prejacent to UTT-T. This is precisely the relation expressed by perfect morphology in the context of conditional modals and in the counterfactual readings of past tense modals in Spanish.

A number of questions relating to compositionality remain open for further research. They relate mainly to the mechanism we have labelled "tense raising", which allows for material originating and being interpreted in the prejacent to be realised on the modal, and to the possibility exhibited by simple infinitives embedded under perfective past modals in Spanish to be interpreted as perfect infinitives. 


\section{References}

Abusch, D. (2004). On the temporal composition of infinitives, in J. Guéron ; J. Lecarme, (eds), 27-54.

Alonso-Ovalle, L. (2002). Spanish DE-clauses are not always in the right mood, in J. Quer et al., (eds), Romance Languages and Linguistic Theory 2001, Amsterdam : John Benjamins.

Bertinetto, P.-M. (2000). The progressive in Romance, as compared with English, in O.Dahl, (ed.), Tense and Aspect in the Languages of Europe, Berlin : Mouton/de Gruyter, 559-604.

Bonomi, A. ; Del Prete, F. (2008). Evaluating future-tense sentences in changing contexts, Ms. University of Milan.

Boogaart, R. (2005). The past and perfect of epistemic modals, submitted to

Cahiers Chronos 2005.

Borgonovo, C. (2008). Modales ambiguos, Ms, Université Paris 8/Université de Laval.

Borgonovo, C. \& Cummins, S. (2007). Tensed Modals, in J. Eguren ; O. Fernández Soriano, (eds), Coreference, Modality, and Focus, Amsterdam : John Benjamins, 1-18.

Bosque, I. (1999). ¿Qué sabe el que sabe hacer algo? Saber entre los predicados modales, in K. Korta ; F. García Murga, (eds), Palabras. Victor Sánchez de Zavala in memoriam. Filosofía 3 (EHU), 303-323.

Cinque, G. (1999). Adverbs and Functional Heads. A Cross Linguistic Perspective, Oxford : Oxford University Press.

Condoravdi, C. (2001). Temporal interpretations of modals. Modals for the present and for the past, in D. Beaver et al. (eds), The Construction of Meaning, Stanford : CSLI Publications., 59-88.

Copley, B. (2002). The Semantics of the Future, Ph.D. dissertation, MIT.

Copley, B. (2008). Temporal orientation in conditionals, in J. Guéron ; J. Lecarme (eds), 59-78.

Demirdache, H. ; Uribe-Etxeberria, M. (2006). Scope and anaphora with time arguments: the case of 'perfect modals', to appear in H. Harley ; R. Folli, (eds), Lingua 118.

Demirdache, H. ; Uribe-Etxeberria, M. (2008). Morfosintaxis e interpretación de los verbos modales, in A. Carrasco Gutiérrez, (ed.), Tiempos compuestos y formas verbales complejas, Madrid-Frankfurt : Iberoamericana,

Dowty, D. (1979). Word Meaning and Montague Grammar, Dordrecht : Kluwer.

Hacquard, V. (2006) Aspects of Modality. Ph.D. dissertation, MIT.

von Fintel, K. (1999). The presupposition of subjunctive conditionals, in U.Sauerland ; O.Percus, (eds), The Interpretive Tract, MIT Working Papers in Linguistics, 29-44. 
von Fintel, K. (2005). Modality and Language, to appear in Encyclopaedia of Philosophy, $2^{\text {nd }}$ edition.

von Fintel, K. ; Iatridou, S. (2003), Epistemic containment, Linguistic Inquiry 34, 2 : 173-198.

von Fintel, K. ; Iatridou, S. (2008). How to say ought in foreign: the composition of weak necessity modals, in J. Guéron ; J. Lecarme, (eds), 115-142.

Guéron, J. ; Lecarme, J., (eds), (2004). The Syntax of Time, Cambridge, Mass.:

MIT Press.

Guéron, J. ; Lecarme, J., (eds), (2008). Time and Modality, Berlin : Kluwer.

Iatridou, S. (2000). The grammatical ingredients of counterfactuality, Linguistic Inquiry 31, 2 : 231-270.

Kamp, H. ; Reyle, U. (1993). From Discourse to Logic, Dordrecht : Kluwer.

Jacobson, P. (2006), I can't seem to figure this out, in B. Birner ; G. Ward, (eds), Drawing the Boundaries of Meaning: Neo-Gricean Studies in Semantics and Pragmatics in Honor of Laurence R. Horn, Amsterdam : John Benjamins, 157-175.

Kaufmann, S. (2005). Conditional truth and future reference, Journal of Semantics $22: 231-280$.

Kaufmann, S. ; Condoravdi, C. ; V. Harizanov, V. (2006). Formal approaches to modality, in W. Frawley, (ed.), The Expression of Modality, Berlin : Mouton/de Gruyter, 71-106.

Kratzer, A. (1981). The notional category of modality, in H.-J. Eikmeyer ; H. Rieser, (eds), Worlds, Words, and Contexts, Berlin : de Gruyter, 38-74.

Laca, B. (2005a) Périphrases aspectuelles et temps grammatical dans les langues romanes, in H. Bat-Zeev Schyldkrot ; N. Le Querler, (éds), Les périphrases verbales, Amsterdam : John Benjamins, 47-66.

Laca, B. (2005b). Tiempo, aspecto y la interpretación de los verbos modales en español, Lingüistica (ALFAL) $17: 9-43$.

Papafragou, A. (2005). Epistemic modality and truth conditions, in A. Klinge ; Müller, (eds), Perspectives on Modality, Amsterdam : John Benjamins. 1688-1702.

Smith, C. (1991). The Parameter of Aspect, Dordrecht : Kluwer.

Smith, C. (2004). The domain of tense, in J. Guéron ; J. Lecarme, (eds), 597620.

Smith, C. (2008) Time with and without tense, in J. Guéron ; J. Lecarme, (eds), 227-249.

Steedman, M. (1997). Temporality, in J. v. Benthem ; A. ter Meulen, (eds), Handbook of Logic and Language, London : Elsevier, 895-939.

Stowell, T. (2004). Tense and Modals, in J. Guéron ; J. Lecarme, (eds), 621636. 
Tasmowski, L. (1980). Un devoir épistémique. Travaux de linguistique 7 : 43-58.

Thomason, R. (1984). Combinations of tense and modality, in D. Gabbay ; F. Guenthner, (eds), Handbook of Philosophical Logic: Extensions of classical logic, Dordrecht : Reidel, 135-165.

Werner, Th. (2003). Deducing the Future and Distinguishing the Past: Temporal Interpretation in Modal Sentences in English. $\mathrm{PhD}$ Dissertation, Rutgers University. 